perfect, hearing is as yct not so fully appreciated as it should be. It cannot be too strongly insisted upon and taught that loss of hearms: power may be due to causes other than those which include a loss of a portion of the membrana tympani.

In the article upon bibble remedies in aural suryery, the author makes some strong and, we think, periectly justifiable remarks upon the indiscriminate use of pilocarpin in the treatment of diseases of the ear. That this drus, useful as it undoubtedly is in a few cases of car discatse, should have been used with such frequency, and in so many and w diverse pathological conditions of the ear, is, to say the least, to be sincerely regretted by all who have the welfare of aural surgery truly at heart. For does not such an indiscriminate and unscientitic employment of any remedy, be the remedy what it may, throw discredit upon the profession at large?

The author also makes some scathing remarks upon the removal of the turbinated bodies for the relief of deafness and tinnitus-remark, which, although they may not receive unqualified acceptance, are "Ill worthy of perusal.

Paper No. XVIII. deals with the important and interesting subject of hysterical (so-called) and functional deafness. Several historich of cases scen by the author are given, and remarks made upon the management and treatment of these interesting conditions.

For the removal of naso-pharyngeal adenoid vegetations in patients over eight or nine years of are, the author thinks that the steel nail should always be used. Nany will, no doubt, disagree with this method of practice, and will elect other instruments for the purpose. Whatever instrument, however, be employed the object is the same-to effect as perfect a clearance of all diseased tissue as is possible. In exceptional cases, again (whatever instrument be employed), a second operation may become necessiry, and it is well that this occasional necessity be fully explained to parents, in order, as the author remarks, "to dispel any idea of an imperfectly performed operation."

These various papers, written in the author's well-known style-clear, concise, and to the point--.-will be found well worthy of perusal.

\title{
W. Milligran.
}

Bonnier.-L'Oreill: I. Anatomie; II. Ihysiologit-Physiosinie th Michantimi: III. Physiologie-les Fonctions. ""The Lar : I. Anatomy; II. I'hysiologyPhysiogeny and Mechanism; III. Ihysiology-the Functions.") By l'. Bowiliz. (I'aris : Masson et Cic.)

THESE are three out of five volumes on the subject of the ear, contributcd by Dr. P'. Bonnicr, as part of a scientific encyclopedia prepared under the direction of M. Léauté. Those who have read the author's contributions to the meetings of the I'aris Laryngological and Otological Society, as reproduced from time to time in the JOURNAI OF LARIN(;OLOGY, will be prepared to welcome these volumes as from the hand of an enthusiast, well worthy of the attention of anyone who desires to find in the specialty of otology some food for thought over and above the dail; round and common task. 
The first, or anatomical, volume is devoted to a description of the human ear, its development, the anatomy of the temporal bone, the auricle, meatus, middle and internal ear, the central course of the cochlear and vestibular fibres, and the cerebral cortical centres with which they are connected. There are large numbers of excellent illustrations, including the blood vessels and lymphatics of the auricle, but not the neves. There is an interesting chapter on the various hila; among other points the membrane of Corti as a cupola formation built on the anditory hair cells, is clearly, if somewhat schematically, brought out. There is an excellent diagram of the connections of the cochlear and restibular nerves with the cerebral nuclei and cortex, the vestibular one being traced to the Rolandic convolutions, where the writer maps out a ortical centre for equilibration. [This accords well with some comparaively recent experimental observations of Ewald's.-REv.]

In the second volume the physiogeny or evolution of the auditory organ throughout the whole animal kingdom is treated in such a way as to show that it has been a labour of love to the writer. The most interesting stages are, perbaps, those found in the fishes in relation to the lateral line and the swim-bladder, the latter functioning, of course, in response to indications of depth in the water given by the equilibrial portions of the internal ear. The enormous size of the otolith in the saccule of many fishes is very striking. The writer analyzes the different forms of tactile stimulus which the equilibrial organ is capable of receiving, as (1) sensation of simple contact, touch; (2) sensation of periodic pressure, seismasthesia; (3) sensation of pressure of surrounding and superincumbent liquid, baresthesia; (4) the same kind of pressure, but periodic, sciscesthesia. Dr. Bonnier combats the Helmholtz theory of the function of the cochlea, refusing to consider it in any other light than that of a "registering" mechanism, analogous to Marey's tambour and style, which analyzes without decomposing the compound wave. $\mathrm{He}$ docs not seem to us to disprove the possibility of the individual fibres of the basilar ligament vibrating in consonance with their proper tones and reinforcing their effect. One very interesting chapter deals with the various reflexes which take place in the organs of hearing-intrinsic reflexes of compensation, of accommodation, of interception; extrinsic reflexes through the great auricular, the pneumogastric, the auriculotemporal, the glosso-pharyngeal, the chorda tympani, the vestibular, the oculo-motor, the citricular, the saccular, and the cochlear nerves.

The work as a whole is pervaded by a tone of originality in conception as well as in the interpretation of facts already recognized. The details are accurate and clearly expressed, while the illustrations are numerous and instructive.

Dundas Grant.

\section{The American Year Book of 'Tratment. (Gould.) (Rebman l'ublishing Co., II, Adam Street, Adelphi, W.C.)}

In this the second year of its existence, "Gould's Year Book" gives good evidence of its sound basis, the present volume being in every respect quite equal to-if it does not even exceed-last year's production. The editors still continue to follow the same excellent method and system 